\title{
Microbial landscapes
}

\section{Joana Ricou}

Centre for Philosophy of Science of the University of Lisbon, Portuguese-American Post-Graduate Society, Lisboa, Portugal Correspondence to: Joana Ricou. Centre for Philosophy of Science of the University of Lisbon, Portuguese-American Post-Graduate Society, Lisboa, Portugal. Email: jiricou@gmail.com.

Submitted Dec 01, 2016. Accepted for publication Apr 25, 2017.

doi: 10.21037/cdt.2017.05.06

View this article at: http://dx.doi.org/10.21037/cdt.2017.05.06

We are made of many parts and many types of parts. Some parts are very old, others are very new, and most will only be a part of us for a little while. I'm interested in the idea that we each are many - and that from moment to moment, we shift, split, merge, cooperate, compete with or ignore ourselves.

In recent years, we've learned that a significant number of our parts are not even human. The collection of microscopic beings that are an integral part of our biology—known as the microbiome-have only begun to yield new insights into who we are and how we fit in the world. The differences in our individual microbiomes speak of our unique histories and selves while the similarities reveal connections between individuals, across borders and generations. In my work, I explore the microbiome as a

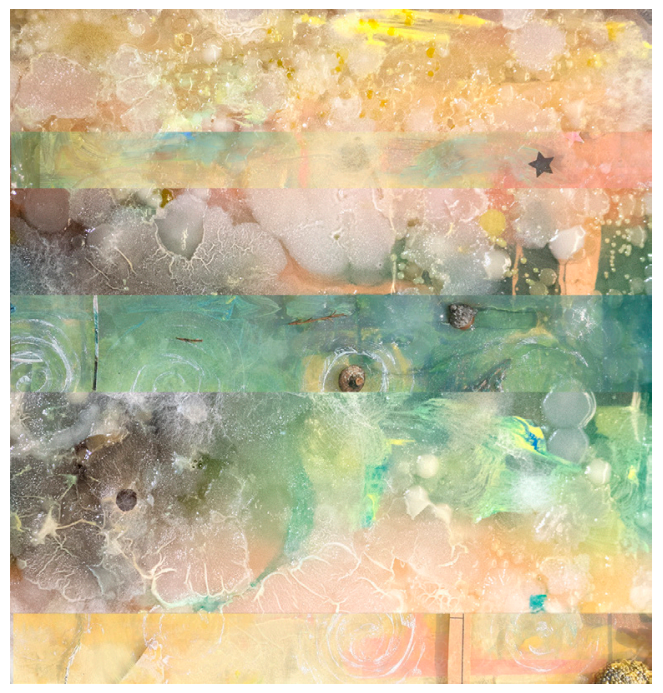

Figure 1 Combining painting, assemblage and microbial culture, this piece captures colors and life from all over Raleigh. subject and as an artistic medium, to explore how it may inform our sense of self creating portraits and landscapes.

In the works (Figures 1-3) presented here, I combine microbial samples from different sites carried by debris and samples of persons that inhabit those spaces, with an artistic sensibility for composition, color and paint. The result is a unique type of landscape, where the individual and the environment, the figure and ground, are indistinguishable.

I moved from Portugal to America to study art and biology at Carnegie Mellon University, where I had the opportunity to work both in a lab and in an art studio. I am inspired by research articles and news and often contact researchers directly to learn about their motivations. In the studio, I build on these ideas to form questions about identity. I am interested in the intersection between art and

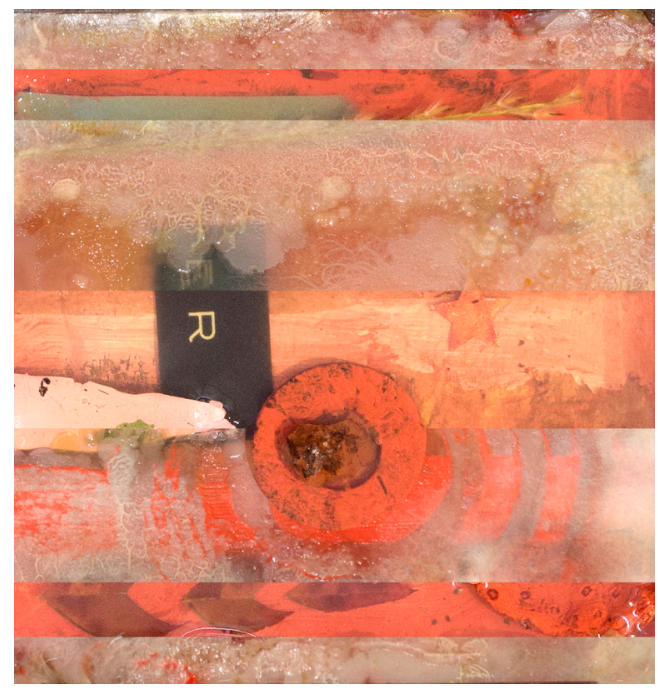

Figure 2 Created from detritus and swabs collected from the spaces and people at North Carolina State University. 


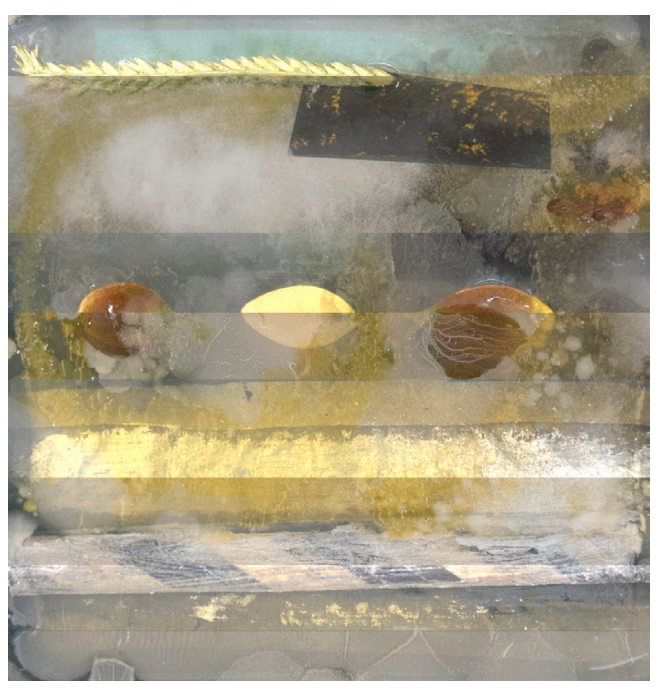

Figure 3 An unusual self-portrait: created from detritus and swabs collected from the streets of Brooklyn and the artist.

science and each can support and contribute to work. This has driven my work in science, art and education and has led to collaborations with galleries, schools and museums

Cite this article as: Ricou J. Microbial landscapes. Cardiovasc Diagn Ther 2017;7(6):645-646. doi: 10.21037/cdt.2017.05.06 in internationally, including the Andy Warhol Museum, the Carnegie Science Center, Centro Cultural de São Paulo, Children's Museum of Pittsburgh and the Ponce Museo de Arte (Puerto Rico). (www.joanaricou.com).

\section{Acknowledgements}

This was only possible through the support of Dr. Rob Dunn and Holly Menninger of North Carolina State University, Dr. Julie Urban and Dr. Marianne Barrier of the North Carolina Museum of Natural Sciences, Dr. William Gaze and Dr. Michiel Vos from Exeter University, Suzanne Anker and Brandon Ballengée of School of Visual Arts (NYC), and many others.

This work was funded by commissions from the North Carolina Museum of Natural Sciences and the Eden Project (Wellcome Trust, UK).

\section{Footnote}

Conflicts of Interest: The author has no conflicts of interest to declare. 